\title{
High-Frequency \\ Trading and Probability Theory
}




\title{
East China Normal University Scientific Reports
}

ISSN: 2382-5715

\section{Chief Editor}

Weian Zheng

Changjiang Chair Professor

School of Finance and Statistics

East China Normal University, China

Email: financialmaths@gmail.com

\section{Associate Chief Editor}

Shanping Wang

Senior Editor

Journal of East China Normal University (Natural Sciences), China

Email: spwang@library.ecnu.edu.cn

\author{
Vol. 1 High-Frequency Trading and Probability Theory \\ by Zhaodong Wang (East China Normal University) \\ and Weian Zheng (East China Normal University) \\ Vol. 2 School Mathematics Textbooks in China: \\ Comparative Study and Beyond \\ by Jianpan Wang (East China Normal University)
}




\section{High-Frequency Trading and \\ Probability Theory}

Zhaodong Wang

Weian Zheng

East China Normal University, China 
Published by

World Scientific Publishing Co. Pte. Ltd.

5 Toh Tuck Link, Singapore 596224

USA office: 27 Warren Street, Suite 401-402, Hackensack, NJ 07601

UK office: 57 Shelton Street, Covent Garden, London WC2H 9HE

\author{
Library of Congress Cataloging-in-Publication Data \\ Wang, Zhaodong. \\ High-frequency trading and probability / Zhaodong Wang, East China Normal University, China \\ and Weian Zheng, East China Normal University, China. \\ pages cm. -- (East China Normal University scientific reports ; v. 1) \\ Includes bibliographical references and index. \\ ISBN 978-9814616508 (hardcover : alk. paper) \\ 1. Investment analysis. 2. Portfolio management. 3. Electronic trading of securities. I. Title. \\ HG4529.W36 2014 \\ 332.64'20285--dc23
}

2014024086

\title{
British Library Cataloguing-in-Publication Data
}

A catalogue record for this book is available from the British Library.

Copyright (C) 2015 by World Scientific Publishing Co. Pte. Ltd.

All rights reserved. This book, or parts thereof, may not be reproduced in any form or by any means, electronic or mechanical, including photocopying, recording or any information storage and retrieval system now known or to be invented, without written permission from the publisher.

For photocopying of material in this volume, please pay a copying fee through the Copyright Clearance Center, Inc., 222 Rosewood Drive, Danvers, MA 01923, USA. In this case permission to photocopy is not required from the publisher.

In-house Editors: Sandhya Venkatesh/Chitralekha Elumalai

Typeset by Stallion Press

Email: enquiries@stallionpress.com

Printed in Singapore 


\section{Contents}

Foreword ix

Preface xi

About the Authors xiii

1. Introduction 1

2. Market Microstructure $\quad 7$

2.1 Trading Products . . . . . . . . . . . . . . 7

2.2 Trading Model . . . . . . . . . . . . . . . . . 11

2.2.1 Continuous Trading . . . . . . . . . . . . . . 12

2.2 .2 Auction . . . . . . . . . . . 15

2.3 Market Data Information . . . . . . . . . . . 21

2.4 Trading Interface . . . . . . . . . . . . . . . . . . . . . . 24

2.5 Risk Control . . . . . . . . . . . . . . . . . 29

2.6 Transaction Costs . . . . . . . . . . . . . 35

2.7 Differences with Western Market . . . . . . . 35

3. Some Basic HFT Strategies 37

3.1 General . . . . . . . . . . . . . . . . 37

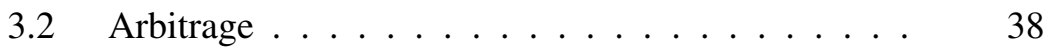

3.2.1 Definition of Arbitrage . . . . . . . . . . . . 38

3.2.2 Different Types of Arbitrage . . . . . . . . . . 40

3.2.3 Process of Arbitrage . . . . . . . . . . . . . . . . 43

3.3 Ticker Tape Trading . . . . . . . . . . . . . . . . . 49

3.4 Market Making . . . . . . . . . . . 52 
3.5 Event Driven . . . . . . . . . . . . . . . 54

3.6 Other Basic Strategies . . . . . . . . . . . 56

4. IT System $\quad 59$

4.1 Challenges . . . . . . . . . . . . . . . 59

4.2 Trading System Design . . . . . . . . . . . . . . . 61

4.2.1 Trading Interface . . . . . . . . . . . . . 62

4.2.2 Trading Process Control . . . . . . . . . 66

4.2.3 Risk Control and Surveillance . . . . . . . . 70

4.2.4 Strategy Implementation . . . . . . . . . . . . . . 75

4.2 .5 Monitoring . . . . . . . . . . . . 77

4.3 Environment . . . . . . . . . . . . . 77

4.3.1 Programming Language . . . . . . . . . . . . 77

4.3.2 Server and Operation System Selection . . . 78

4.3.3 Network Environment . . . . . . . . . . . . 79

4.4 Core Technologies . . . . . . . . . . . . 81

4.4.1 Single-Process vs. Multi-Process . . . . . . 81

4.4 .2 Code Optimization . . . . . . . . . . . . . . 82

4.4.3 Memory Management . . . . . . . . . . 83

4.4.4 Managing CPU Cache . . . . . . . . . 83

5. Stationary Process and Ergodicity 85

5.1 Some Basics of Probability Theory . . . . . . . . 85

5.1.1 Probability Space . . . . . . . . . . . . . . . . 86

5.1 .2 Random Variables . . . . . . . . . . . . . . . . 88

5.1.3 Conditional Probability . . . . . . . . . . . . . . . 89

5.1.4 Two Main Theorems . . . . . . . . . . . . 90

5.1.4.1 The strong law of large number . . . 91

5.1.4.2 The central limit theorem ..... . 92

$5.2 \quad$ Stochastic Process . . . . . . . . . . . . . . 92

5.2.1 Examples of Stochastic Processes . . . . . . 92

5.2.2 Stationary Process and Ergodic Theory . . . 93

5.2.2.1 The strong ergodic theorem . . . . . 95

5.2 .3 Testing Stationarity . . . . . . . . . . . . 97

5.2.4 Semi-Martingales and Filtering Problem . . . 98

5.2.5 Stationary Process as Noises . . . . . . . . 100 
5.3 Time Series Analysis . . . . . . . . . . . . . . . . . 101

5.4 Pair-Trading Revisited . . . . . . . . . . . . . . . 104

6. Stationarity and Technical Analysis 109

6.1 Technical Analysis . . . . . . . . . . . . . . 111

6.2 Logarithmic Return is Stationary . . . . . . . . 113

6.3 Moving Average and Exponential Moving Average . . . . . . . . . . . . . . 115

6.4 Bollinger Bands . . . . . . . . . . . 120

6.5 Moving Average Convergence-Divergence . . . . . 123

6.6 Rate of Change . . . . . . . . . . . . . . . . . . . 126

6.7 Relative Strength Index . . . . . . . . . . . . 127

6.8 Stochastic Oscillators . . . . . . . . . . . . . 129

6.9 Directional Movement Index . . . . . . . . . . . 133

6.10 Parabolic SAR . . . . . . . . . . . . . . 138

7. HFT of a Single Asset 141

7.1 Stochastic Integral of Stationary Processes . . . . . 142

7.1.1 Ito-Riemann Sums and Their Limit . . . . . 142

7.1.2 Profit of HFT and Strong Ergodic Theorem . . . . . . . . . . . 143

7.1.3 Sharpe Ratio Test for HFT . . . . . . . . . . . . . 147

7.2 Two Examples . . . . . . . . . . . . . . . . . . 149

7.2.1 The First Example . . . . . . . . . . . . . 149

7.2.2 The Second Example . . . . . . . . . 151

8. Bid, Ask and Trade Prices 155

9. Financial Engineering 159

9.1 Mathematical Finance . . . . . . . . . . . . . . . 159

9.2 Statistical Finance . . . . . . . . . . . . . . . . . 162

9.3 Behavioral Finance . . . . . . . . . . . . . 163

9.4 Computational Finance . . . . . . . . . . . 164

10. Debate and Future 167

$\begin{array}{ll}\text { References } & 171\end{array}$

$\begin{array}{ll}\text { Index } & 175\end{array}$ 


\section{This page intentionally left blank}




\title{
Foreword to East China Normal University Scientific Reports
}

\begin{abstract}
Founded in 1951, as a result of merging of several old universities in Shanghai (including St. John's University founded in 1879), East China Normal University (ECNU) becomes one of the most prestigious universities in China. Our faculty members have acquired high academic reputations in a number of scientific research areas.

ECNU Scientific Reports, a book series edited by the editorial office of Journal of ECNU and published by World Scientific Publishing Co., present valuable results and significant progresses in scientific researches. We hope that this book series will serve as an international platform for scientific research, particularly inter-disciplinary research.

I am delighted to see the publication of the first volume, HighFrequency Trading and Probability Theory; and would like to sincerely congratulate the authors. I expect that more and more valuable volumes of the series will appear in the near future, so that the international scientific world will benefit from our research.
\end{abstract}

Qun Chen

President of East China Normal University

Shanghai, China 


\section{This page intentionally left blank}




\section{Preface}

There have been quite a few publications on High-Frequency Trading (HFT). However, few of them discussed the detailed strategies and algorithms of HFT. From our point of view, HFT is an application of high technology and mathematics to the financial market. Based on our practice in the Chinese futures market, we will show mainly three things in this book:

(1) Some facts and technical details of the IT system design for HFT, some of which have not been seen in literature until this point.

(2) HFT has the ergodic theory of stationary process as its mathematical background.

(3) A trader can use technical analysis to repeatedly trade one financial derivative and make statistical arbitrage according to the strong ergodic theorem.

Due to its remarkable profitability, the algorithms of HFT were considered highly confidential and have not been well-studied in the academic world. Just as in Chinese proverb "throwing out a brick in order to attract the others throwing gems", we hope that this book will attract more researchers to study the scientific background of HFT. We will concentrate our discussions of the examples of the Chinese futures market. However, the general principles apply to other markets as well.

We assume that our readers are aware of some basic calculus. The material of this book was discussed at the School of Finance and Statistics, East China Normal University three times in three semesters. We would like 
to thank Professor Shujin $\mathrm{Wu}, \mathrm{PhD}$ students Si Bao, Shi Chen, Chang Liu, Shuai Wang and Yu Zhou for various insightful discussions and technical assistances. We particularly thank Ms. Xiaolin Guo who videotaped the first author's lectures which form the first part of this book, and thank Ms. Eileen Raney who assisted us to edit the original English manuscript. This work is partially supported by the 111 project (B14019) in China.

Zhaodong Wang and Weian Zheng School of Finance and Statistics East China Normal University Shanghai 200241, China December 2013 


\section{About the Authors}

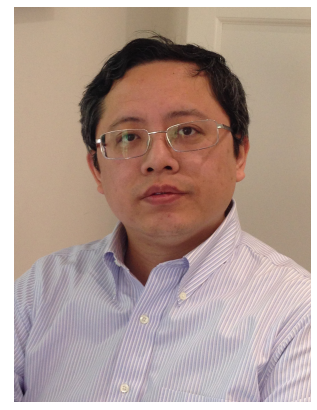

Zhaodong Wang obtained his $\mathrm{PhD}$ degree in Computer Science from Shanghai Jiao Tong University. $\mathrm{He}$ is an expert in high performance system design. He was the CEO of Shanghai Futures Information Technology Corp. Ltd. At that time, he designed the trading system for Shanghai Futures Exchange, China Finance Futures Exchange and many other systems in financial area. Later, he set up a hedge fund focus on high-frequency trading.

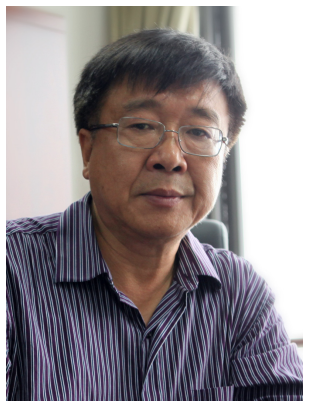

Weian Zheng is a State Endowed Professor at ECNU and Professor Emeriti at University of California, Irvine, USA. He had Docteur d'état ès Sciences Mathématiques degree from University of Strasbourg, France. He has a few known results in probability theory, including (with P. A. Meyer) the tightness criteria for laws of semi-martingales and (with T. J. Lyons) the forward-backward decomposition of symmetric Markov processes. With Y. Shen, he used probability theory to reduce the famous Monge-Kantorovich mass transfer problem to a boundary value problem of partial differential equation and solved this problem in the plane. He was born in Shanghai and grew up during the epoch of Chinese Cultural Revolution. He was unable to continue his study after the first year of middle school. He studied mainly by himself to become a mathematician. 